\title{
Adaptive Behaviour and Paddle Tennis: A Case Study of Down's Syndrome
}

\author{
Ricardo De la Vega ${ }^{1}$, Roberto Ruíz ${ }^{2}$, Maria De la Rocha, \\ Jesús Onrubia ${ }^{4}$, Oswaldo Rivera ${ }^{1}$ \\ ${ }^{1}$ Department of Physical Education, Sports and Human Motricity, \\ Autonomous University of Madrid, Madrid, Spain \\ ${ }^{2}$ Department of Evolutionary and Educational Psychology, \\ Autonomous University of Madrid, Madrid, Spain \\ ${ }^{3}$ Vicalvaro's Health Center, Madrid Health Center, Madrid, Spain \\ ${ }^{4}$ Sport and Physical Activity, Disability and Social Integration, \\ Autonomous University of Madrid, Madrid, Spain \\ Email: ricardo.delavega@uam.es
}

Received September 19 ${ }^{\text {th }}, 2013$; revised October 19 ${ }^{\text {th }}, 2013$; accepted October $26^{\text {th }}, 2013$

Copyright (C) 2013 Ricardo De la Vega et al. This is an open access article distributed under the Creative Commons Attribution License, which permits unrestricted use, distribution, and reproduction in any medium, provided the original work is properly cited.

\begin{abstract}
Adaptive behaviour is one of the key elements to diagnose intellectual disability. In addition, these behaviors are crucial in order to operate on the daily life. As a population with a high risk of developing a sedentary lifestyle, adapted physical activity programs for people and children with intellectual disability are needed. Therefore the aim of this study is to assess the influence of adapted paddle tennis intervention program on the adaptive behaviour of a child with Down's syndrome. In a case study of child with Down's syndrome (male, Caucasian, age $=4.5$ years), he participated on a paddle tennis program with a length of 12 weeks. The child's parents assessed the adaptive behaviour before and after the program through the Adapted Behaviour Scale (ABS-S:2). Obtained data showed that three domains presented a positive increasing. Parents reported that physical development increased from 19 to 23.5, and this increase was corroborated by the instructor (post score $=23.8$ ). Moreover, language development increases from 18.5 to 28 (parents). The paddle tennis instructor perceived an increase in speaking abilities after the program. The self-management domain also showed an increase from 8 to 17 . The adapted paddle tennis program is suitable for promoting physical activity and for improving adaptive behaviour in children with intellectual disabilities.
\end{abstract}

Keywords: Adaptive Behaviour; Paddle Tennis; Down’s Syndrome; Physical Activity

\section{Introduction}

The American Association on Intellectual and Developmental Disabilities (2002) establishes that the diagnosis of disability is composed of two elements: the intellectual functioning and the adaptive behaviour. In this sense, the person's intellectual coefficient (IQ) did not diagnose an intellectual disability unless the assessment of the adaptive behavior is included, and this perspective is known as the functioning model of intellectual disability. Adaptive behaviour is defined as the compound of conceptual, social and practical abilities which a person learned in order to effectively operate on his daily life (Luckasson et al., 2002). These abilities are crucial for the person's integration and general functioning (Goldberg, Dill, Shin, \& Nhan, 2009) and close related with the person's adaptation to the daily life. As consequence, differences on the adaptive behaviour represent a major impediment to lead an independent life (Soenen, Van Berckelaer-Onnes, \& Scholte, 2009). It is considered that these impediments are manifested early in the person's life and persist throughout life unless the child participates in an intervention program (Chadwick, Cuddy, Kusel, \& Taylor, 2005). Intervention programs based on the IQ per- pective are static, limiting in this way a possible improvement. Contrary, the adaptive behaviour could increase as the result of an intervention program.

One of the common pathologies associated with intellectual disability is Down's syndrome. This syndrome results from a chromosomal abnormality in which a person' cell nucleons present 47 chromosomes instead of 46; and the exceeded chromosome belongs to the $21^{\text {st }}$ pair. This genetic despair brings out modifications on the development and functioning of organs and systems. These modifications are manifested during prenatal and postnatal stages. The central nervous system CNS is one of the most common affected systems. Especially, brain and cerebellum are affected, and for this reason in a constant way, a person with Down's syndrome presents, in a variable level, intellectual disability and psychomotor deficiencies. Especially, Down's syndrome genetic alteration is close related with deficiencies in the orthopedic and cardiovascular systems (Sanyer, 2006). Children with Down's syndrome have had little participation in leisure and sport activities. In addition, their main leisure activities are mainly sedentary and solitary (Oates, Bebbington, Bourke, Girdler, \& Leonard, 2011). Furthermore, 
their interpersonal relations with other children are restricted. It has been reported that children with Down's syndrome have a few number of friends (D'Haem, 2008). With an approximate incidence of one of 650 - 1000 births, they are a population with a high risk of developing a sedentary lifestyle, and consequently a higher risk to being obese (De, Small, \& Baur, 2008). Individuals with intellectual and developmental disabilities, as Down's syndrome, are in need of effective physical fitness training programs (Lotan, Yalon-Chamovitz, \& Weiss, 2009). Some limitations for practicing sports highlighted by Sanyer (2006) in children with Down's syndrome are the need to involve health and sport sciences professionals in the management and care of people with intellectual disability (D'Haem, 2008). Therefore, an adapted paddle tennis program, monitored by qualified personnel, could be highly beneficial. Regular physical activity improves the cardiovascular and muscle function. Additionally, physical activity also appears to decrease depression, and enhance feelings of well-being (Franklin, Whaley, \& Howley, 2000). The objective of the present study was to describe the effect of an organized adapted paddle tennis program on the adaptive behaviour of a child with DS.

\section{Methods}

\section{Participants}

Participated in the study a child with Down's syndrome named Carlos (male), age (4.5 years), race (Caucasian). Carlos lives with his parents, and did not have any experience practicing paddle tennis or physical activity. We contact with Carlos' parents through de Adapted Paddle Tennis School (Madrid, Spain) which is part of the official schools of the Paddle for All Association. Parents and the paddle tennis' instructor voluntary participated and provided informed consent. This study was approved by the ethical committee of the Paddle for All Association.

\section{Measures}

We used the Spanish version (García, 2001) of the Adaptive Behaviour Scale (ABS-S:2; Lambert, Nihira, \& Leland, 1993). The scale is based on the performance of people with intellectual disability with ages range from 3 to 69 years. The scale assesses and describes the adaptive behaviour, obtaining a profile with eight domains: Independent functioning, Physical development, Language development, Numbers and time, Domestic activity, Self-direction, Responsibility, and Socialization. This instrument allowed us to identify behaviour strengths and deficiencies. Moreover, it facilitates to assess the person' progress while participating in an intervention program (Hardiman, Guerin, \& Fitzsimons, 2009). The ABS-S:2 has a reliability coefficient of 0.96 (Medina, 2010). The ABS-S:2 scale is compound of two parts, the first to assess the adaptive behaviour, and a second to assess the maladaptive behaviour, in our study we focused on the first part, data obtained from the second part will not be used, neither in a further study.

\section{Procedure}

Using the ABS-S:2, the parents assessed Carlos before and after the intervention program. Parents were interviewed by the research staff in order to obtain information related to Carlos. Separately, each parent completed the scale. The paddle tennis instructor was interviewed at the end on the intervention to obtain information of Carlos related to his physical and technical issues, his behaviour during the sessions, and the interaction with him before and after the program.

The intervention consisted on 12 adapted paddle tennis classes (one each week) during the months of April to June of 2012. The class duration was 45 minutes and consisted on three stages, first the warm-up, second the paddle tennis drills and technique, and third the feedback and leisure part. This structure focus on satisfy the needs of physical activity and wellbeing issues.

\section{Results}

To assess the intervention program effect on the adaptive behaviour we describe the data obtained with the ABS-S:2. Descriptive data of the ABS-S:2 domains are presented in Table 1.

In general, the results showed that Carlos presented deficiencies in the adaptive behaviour domains, some of these deficiencies are major ones, as in the case of Independent Functioning. After completing the adapted paddle tennis program Carlos obtained a score of 61 from a maximal of 119. Physical development showed an increase after the intervention from 19 to 23.5 , with a maximum domain score of 24 . This is a prosperous result for the intervention program, due to the increase in this domain which can be presented as a Carlos' strength. This increase on the physical development was confirmed by observations performed by the research staff and with the information obtained with the instructor. In addition, other domain to consider was the Language development, results showed an improvement before the intervention, with an increase from 18.5 to 28. This improvement was confirmed by the instructor. Self-direction domain also improves from 8 to 17 (maximum score of 23), which can be considered as other adaptive behaviour strength.

\section{Discussion}

From a practical point of view the adapted paddle tennis program had an effect on Carlos' adaptive behaviour. These effective results allowed us to consider this type of intervention as a viable option to promote the sport practice in a population characterized by a sedentary lifestyle. Results of the ABS-S:2 scale offered a general view of the strengths and deficiencies of

\section{Table 1.}

Domains scores of the adaptive behaviour scale ABS-S:2, descriptive statistics mean scores pre-post intervention and maximum domains score.

\begin{tabular}{cccc}
\hline ABS-S:2 Domains & Pre $^{\mathrm{a}}$ & Post $^{\mathrm{a}}$ & Max $^{*}$ \\
\hline I: Independent funtioning & 48.5 & 61 & 119 \\
II: Physical develompment & 19 & 23.5 & 24 \\
IV: Language development & 18.5 & 28 & 43 \\
V: Numbers and time & 4 & 5.5 & 14 \\
VI: Domestic activities & 3.5 & 5 & 23 \\
VIII: Self-direction & 8 & 17 & 23 \\
IX: Responsability & 2.5 & 5.5 & 10 \\
X: Socialization & 8.5 & 8 & 26 \\
\hline
\end{tabular}

Note: ${ }^{a}$ Mean scores from parents' assessment; ${ }^{*}$ Maximun score per domain. 
a person's abilities to effectively conduct his daily life. The objective of this study was to describe, as a pilot study, the effect of an adapted paddle tennis program on the adaptive behaviour of a child with Down's syndrome. Due to Carlos' young age, just one year above the minimum age of the scale, the obtained domain scores are majorly low, showing deficiencies on these behaviors (Goldberg, Dill, Shin, \& Nhan, 2009). Nevertheless, results related to Physical development showed an improvement after the program, accordingly to the increased scores, and this domain can be considered as a child' strength. Being a sport related intervention, specifically paddle tennis, is not surprising that the physical development improves before the program. Moreover, the scores of this domain obtained before the intervention were higher. Our results allowed us to suggest that this sport based programs can be integrated into the leisure activities of children with Down's syndrome. In reference to language development, we considered that the program allows the children to interact with other people outside their family. In addition, this interaction improves the language abilities, and this issue is relevant if we consider that children with Down' syndrome have a low number of friends, and mostly perform solo activities (Oates et al., 2011). As a sport based program it is possible to fight against the sedentary lifestyle of this population and helps them to obtain the benefits of the sport practice (De, Small, \& Baur, 2008). The program included three stages, and as an adapted program it included important issues as participation, social support and self-rewarding (D’Haem, 2008). Due to the need to satisfy the demand of practicing physical activity (Lotan, Yalon-Chamovitz, \& Weiss, 2009), the program is feasible and suitable to fight against children' sedentary lifestyle. Moreover, as an intervention program adapted to the intellectual disability population, the program offers the service of qualified personnel. Contrary to a general paddle tennis class, our pilot intervention focuses on satisfying the needs of the persons with intellectual disability, especially at early ages. Although it was a short length intervention, only 12 sessions, we observed improvements in the adaptive behavior, and further studies which use a longer length intervention are needed. The adaptive behaviour research allows using a case study methodology. Contrary to the IQ classification approach, which is static, the adaptive behaviour allows us to identify strengths and deficiencies along a wide range of domains. Nonetheless, it will be interesting for further research to analyze the effect of the adapted paddle tennis classes with a larger group of participants.

The present study does have a number of limitations. The case study approach, which can be considered for studying adaptive behavior, is not as accurate in order to study the effect of adapted sports and physical activity on intellectual disabilities. However, having a participant that didn't have any previous paddle experience was adequate for our purpose. The lack of comparisons with other children, with or without intellectual disabilities is also a limitation. Future research may therefore be warranted by comparing what differences, if any, the practice of physical activity of adapted sports plays in the adaptive behavior on larger groups. Furthermore, it would be interesting to consider the effect of adapted paddle tennis during a longer period of time or with more frequent sessions, instead of just one week.

The adapted paddle tennis classes are positive not just to improve the physical and psychomotor skills, but also to be served as an interactive space for leisure.

\section{Acknowledgements}

This research has been subsidized by the Fundación Repsol, through the "Adaptive Behaviour and a Paddle Tennis: a case study of Down's syndrome” project (Fundación Deporte Joven, Consejo Superior de Deportes (CSD), Asociación Padelparatodos (ASPADO), Universidad Autónoma de Madrid (UAM).

\section{REFERENCES}

American Association on Metal Retardation (2002). What is intellectual disability? http://www.aamr.org/content_100.cfm?navID=21

Chadwick, O., Cuddy, M., Kusel, Y., \& Taylor, E. (2005). Handicaps and the development of skills between childhood and early adolescence in young people with severe intellectual disabilities. Journal of Intellectual Disabilities Research, 49, 877-888. http://dx.doi.org/10.1111/j.1365-2788.2005.00716.x

D'Haem, J. (2008). Special at school but lonely at home: an alternative friendship group for adolescents with Down syndrome. Downs Syndrome Research and Practice, 12, 107-111. http://dx.doi.org/10.3104/practice.2012

De, S., Small, J., \& Baur, L. (2008). Overweight and obesity among children with developmental disabilities. Journal of Intellectual Developmental Disability, 33, 43-47. http://dx.doi.org/10.1080/13668250701875137

Franklin, B. A., Whaley, M. H., \& Howley, E. T. (2000). ACSM's guidelines for exercise testing and prescription (6th ed.). Philadelphia: Lippincott Williams \& Wilkins.

García, M. (2001). Las personas con retraso mental y su diagnóstico: Traducción, adaptación y valoración de la Escala de Conducta Adaptativa ABS S:2 y del método de Evaluación de las "Áreas de Habilidades Adaptativas AAA”. Ph.D. Thesis, Burgos: Burgos University.

Goldberg, M. R., Dill, C. A., Shin, J. Y., \& Nhan, N. V. (2009). Reliability and validity of the Vietnamese Vineland Adaptive Behavior Scales with preschool-age children. Research in Development Disabilities, 30, 592-602. http://dx.doi.org/10.1016/j.ridd.2008.09.001

Hardiman, S., Guerin, S., \& Fitzsimons, E. (2009). A comparison of the social competence of children with moderate intellectual disability in inclusive versus segregated school settings. Research in Development Disabilities, 30, 397-407.

http://dx.doi.org/10.1016/j.ridd.2008.07.006

Lambert, N., Nihira, K., \& Leland, H. (1993). Adaptive Behavior Scales-school: Second edition. ABS-S.2. Austin: PRO-ED, American Association on Mental Retardation.

Lotan, M., Yalon-Chamovitz, S., \& Weiss, P. (2009). Improving physical fitness of individuals with intellectual and developmental disability through a Virtual Reality Intervention Program. Research in Development Disabilities, 30, 229-239. http://dx.doi.org/10.1016/j.ridd.2008.03.005

Luckasson, R., Borthwick-Duffy, S., Buntix, W., Coulter, D., Craig, E., Reeve, A., et al. (2002). Manual retardation, Definition, Classification and Systems of supports (10th ed.). Washington: American Association on Mental Retardation.

Medina, M. (2010). Evaluación de la Conducta Adaptativa de las Personas con Discapacidad Intelectual. Valoración y Usos de la Escala ABS-RC: 2. Ph.D. Thesis, Burgos: Burgos University.

Oates, A., Bebbington, A., Bourke, J., Girdler, S., \& Leonard, H. (2011). Leisure participation for school-aged children with Down syndrome. Disability and Rehabilitation, 33, 1880-1889. http://dx.doi.org/10.3109/09638288.2011.553701

Sanyer, O. (2006). Down syndrome and sport participation. Current Sports Medicine Reports, 5, 315-318. http://dx.doi.org/10.1097/01.CSMR.0000306436.13735.cf

Soenen, S., Van Berckelaer-Onnes, I., \& Scholte, E. (2009). Patterns of intellectual, adaptive and behavioral functioning in individuals with mild mental retardation. Research in Development Disabilities, 30, 433-444. http://dx.doi.org/10.1016/j.ridd.2008.04.003 